\title{
Front Matter: Volume 11451
}

, "Front Matter: Volume 11451," Proc. SPIE 11451, Advances in Optical and Mechanical Technologies for Telescopes and Instrumentation IV, 1145101 (15 January 2021); doi: 10.1117/12.2591665

SPIE. Event: SPIE Astronomical Telescopes + Instrumentation, 2020, Online Only 


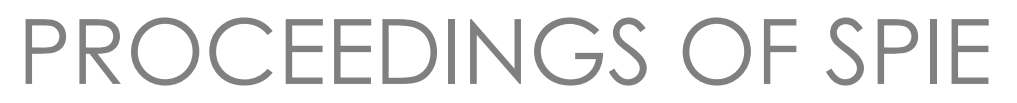

\title{
Advances in Optical and Mechanical Technologies for Telescopes and Instrumentation IV
}

\author{
Ramón Navarro \\ Roland Geyl \\ Editors
}

14-22 December 2020

Online Only, United States

Sponsored and Published by

SPIE

Volume 11451

Part One of Two Parts 
The papers in this volume were part of the technical conference cited on the cover and title page. Papers were selected and subject to review by the editors and conference program committee. Some conference presentations may not be available for publication. Additional papers and presentation recordings may be available online in the SPIE Digital Library at SPIEDigitalLibrary.org.

The papers reflect the work and thoughts of the authors and are published herein as submitted. The publisher is not responsible for the validity of the information or for any outcomes resulting from reliance thereon.

Please use the following format to cite material from these proceedings:

Author(s), "Title of Paper," in Advances in Optical and Mechanical Technologies for Telescopes and Instrumentation IV, edited by Ramón Navarro, Roland Geyl, Proceedings of SPIE Vol. 11451 (SPIE, Bellingham, WA, 2020) Seven-digit Article CID Number.

ISSN: 0277-786X

ISSN: 1996-756X (electronic)

ISBN: 9781510636897

ISBN: 9781510636903 (electronic)

Published by

SPIE

P.O. Box 10, Bellingham, Washington 98227-0010 USA

Telephone +1 3606763290 (Pacific Time) · Fax +1 3606471445

SPIE.org

Copyright (c) 2020, Society of Photo-Optical Instrumentation Engineers.

Copying of material in this book for internal or personal use, or for the internal or personal use of specific clients, beyond the fair use provisions granted by the U.S. Copyright Law is authorized by SPIE subject to payment of copying fees. The Transactional Reporting Service base fee for this volume is $\$ 21.00$ per article (or portion thereof), which should be paid directly to the Copyright Clearance Center (CCC), 222 Rosewood Drive, Danvers, MA 01923. Payment may also be made electronically through CCC Online at copyright.com. Other copying for republication, resale, advertising or promotion, or any form of systematic or multiple reproduction of any material in this book is prohibited except with permission in writing from the publisher. The CCC fee code is $0277-$ $786 \mathrm{X} / 20 / \$ 21.00$.

Printed in the United States of America by Curran Associates, Inc., under license from SPIE.

Publication of record for individual papers is online in the SPIE Digital Library.

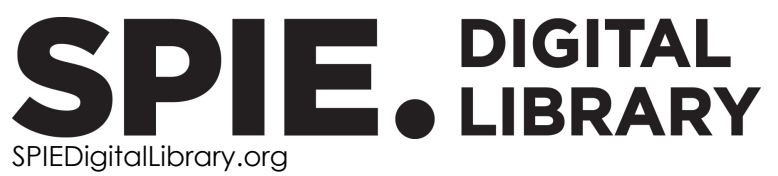

Paper Numbering: Proceedings of SPIE follow an e-First publication model. A unique citation identifier (CID) number is assigned to each article at the time of publication. Utilization of CIDs allows articles to be fully citable as soon as they are published online, and connects the same identifier to all online and print versions of the publication. SPIE uses a seven-digit CID article numbering system structured as follows:

- The first five digits correspond to the SPIE volume number.

- The last two digits indicate publication order within the volume using a Base 36 numbering system employing both numerals and letters. These two-number sets start with $00,01,02,03,04$, 05, 06, 07, 08, 09, OA, OB ... 0Z, followed by 10-1Z, 20-2Z, etc. The CID Number appears on each page of the manuscript. 


\section{Contents}

\section{Part One}

NOVEL AND DISRUPTIVE CONCEPTS

1145107 A decade of NASA strategic astrophysics technology investments: technology maturation, infusion, and other benefits [11451-1]

$1145108 \quad$ NAIR: Novel Astronomical Instrumentation through photonic Reformatting [11451-2]

$1145109 \quad$ Crossing the diffraction limit with an optical amplifier [11451-3]

11451 OA CASTLE: a curved-sensor-based wide-field telescope at Calar Alto [1 1451-4]

$114510 B \quad$ A generalized Offner relay with an accessible pupil [1 1451-5]

NOVEL AND DISRUPTIVE CONCEPTS II

$114510 \mathrm{O} \quad$ An additive manufactured CubeSat mirror incorporating a novel circular lattice [11451-6]

11451 OE Modal noise mitigation in a photonic lantern fed near-IR spectrograph [1 1451-8]

\section{LARGE OPTICS AND SUPPORT SYSTEMS I}

11451 OF ELT secondary mirror manufacturing progress at Safran Reosc [11451-10]

$114510 G$ Design and production of segment mirrors for the Large-Sized Telescopes of the Cherenkov Telescope Array [11451-11]

$11451 \mathrm{OH} \quad$ Application progress of stressed mirror continuous polishing technology in the segments fabrication of telescope primary mirror [11451-12]

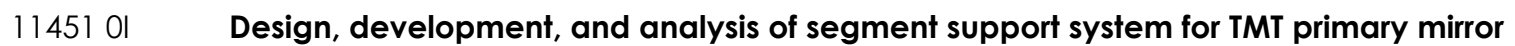
[11451-13]

11451 0J NPF update: light-weight mirror development in Chile [1 1451-14]

11451 OK Primary mirror panels of the Millimetron Space Observatory [11451-16] 
$11451 \mathrm{OL}$ Optics for EUCLID telescope: challenges and developments [11451-17]

11451 ON A new manufacturing system for free form and large optics [11451-19]

1145100 Design and MAIT status of the UH2.2 adaptive secondary mirror [11451-20]

11451 OP Microlenses for astrophotonic instruments manufactured by ultrafast-laser assisted etching [11451-21]

LARGE OPTICS AND SUPPORT SYSTEMS II

$114510 Q$ The ELT M1 support structure from prototype into volume manufacturing: an industrial perspective [11451-22]

11451 OS The coating plant for the segments of the primary mirror of the Extremely Large Telescope (ELT) in Chile [11451-24]

TEST AND METROLOGY OF (SUB-)SYSTEMS I

11451 OV Interferometer for surface figure of large convex hyperboloid mirrors [1 1451-27]

11451 OW CGH for ESO's ELT M2 reference plate: fabrication of high precision CGHs [1 1451-28]

TEST AND METROLOGY OF (SUB-)SYSTEMS II

11451 OY New Fourier CGH coding using DMD generated masks for grayscale and color images [11451-31]

MATERIALS

1145114 Effect of surface condition on the bending strength of cordierite ceramics [11451-38]

1145116 Fundamental characteristics of three-dimensional additive manufacturing products of zero thermal expansion metal [11451-40]

1145118 Precise control of negative thermal expansion in stainless invar type alloy for astronomical telescopes [11451-42]

iv 
1145119 Space environment resistance of thermo-optical properties of low CTE ceramics and glass [1 1451-43]

11451 1 A The primary mirror of the Ariel mission: cryotesting of aluminum mirror samples with protected silver coating [11451-44]

11451 1B CTE homogeneity of ZERODURß in the ELT century [11451-284]

GRATINGS

11451 1C Machined InP immersion grating perfectly covering J-band [1 1451-45]

11451 1D Échelle grating with improved polarization characteristics used for Earth observation [11451-46]

$114511 G \quad$ Ge immersed grating manufacturing and optical verification for the METIS high-resolution spectrograph [11451-49]

COATINGS, FILTERS

$114511 \mathrm{M} \quad$ Primary mirror aluminizing operations at the Large Binocular Telescope [11451-55]

TECHNOLOGIES FOR CRYOGENIC INSTRUMENTS

1145110 A cryogenic actuator for the image derotator on ELT-METIS [11451-60]

11451 1P H2020 opticon WP5 overview: investigating the use of additive manufacturing for the design and build of multifunctional integrated astronomical components [1 1451-61]

\section{ACTIVE INSTRUMENTS}

11451 1W Results of the ELT M1 position actuators validation campaign [1 1451-70]

$114511 \mathrm{X} \quad$ The prospects for applying magnetic smart materials combined with shape memory alloys to produce correctable and deployable space telescopes [11451-71]

1145112 The InfraRed Imaging Spectrograph (IRIS) for TMT: support structure final design [11451-74] 
1145120 A focal-ratio-degradation resistant multimode fiber link using mode-selective photonic lantern [11451-76]

1145121 Initial measurements of focal ratio degradation in ZBLAN fluoride fibers for K band spectroscopy [11451-77]

1145123 Optical fibre pseudo-slits for astronomy [11451-79]

1145124 Multi-core fibre-fed integral field spectrograph (MCIFU) IV: the fiber link [1 1451-80]

1145125 An easily scalable Theta/Phi fiber positioner to reduce risks, lead times, and costs for multiobject spectrographs [11451-81]

1145126 Mix and match as you go: beam switch module that splits wavelengths, scrambles beams, and switches fibers in multiplexed replicated astronomical spectrograph systems such as VIRUS2 [11451-82]

OPTICAL FIBERS, POSITIONERS II

1145127 Design and testing of the MOONS fibre positioning units [11451-83]

1145129 Photonic integrated circuit for absolute metrology [11451-85]

SLIT SPECTROSCOPY AND IMAGE SLICERS

$114512 \mathrm{D} \quad$ Boosting dispersive spectrograph stability 1000x using an interferometer with crossfaded delays [11451-89]

POSTER SESSION: ADDITIVE MANUFACTURING AND CFRP

$114512 \mathrm{H} \quad$ Initial development of high accuracy carbon fiber reinforced plastics (CFRP) reflector segment for the 60-meters submillimeter telescope [11451-115]

$1145121 \quad$ Quality control of the CFRP mirror manufacturing process at NPF [11451-116]

$114512 \mathrm{~J} \quad$ Mitigating print-through effects through an optimized method for CFRP mirror production in Chile [11451-117]

$114512 \mathrm{M}$ Freeform active mirror designed for additive manufacturing [11451-121]

$114512 \mathrm{~N} \quad$ Additive manufacturing: innovative concepts of compliant mechanisms [11451-122] 
POSTER SESSION: MATERIALS

$114512 Q \quad$ Optical materials for space applications [11451-127]

$114512 R \quad$ Lightweighting strategies for main support structures of ELT instrumentation [1 1451-128]

$114512 S$ Characterization of the reflectivity of various black and white materials [11451-129]

\section{Part Two}

POSTER SESSION: OPTICAL FABRICATION

$114512 X \quad$ F-molding: a new production method for largely aspherical mirrors of Cordierite [11451-148]

$114512 Y \quad$ Fabrication of mirror arrays with an ultra-precision cutting technique for a near-infrared integral field unit SWIMS-IFU [11451-149]

$1145130 \quad$ Polishing and testing of TMT reference sphere [11451-151]

$1145131 \quad$ NIRPS: gluing optics with epoxy, lessons learned [11451-153]

1145132 Thermal tests of birefringent plates in molecular adhesion for spatial ultra-violet polarimetry [1 1451-154]

POSTER SESSION: TESTING AND METROLOGY AT COMPONENT OR INSTRUMENT LEVEL

1145138 HARMONI - first light spectroscopy for the ELT: final design of the integral field unit [11451-162]

1145139 HARMONI - first light spectroscopy for the ELT: spectrograph camera lens mounts [11451-163]

$114513 \mathrm{~A}$ Cementing and testing of the 4MOST WFC/ADC doublets [11451-166]

$114513 B$ A metrological characterization of the SPEED test-bed PIAACMC components [11451-168]

$114513 C \quad$ Fabrication and characterization of aluminum image slicers [11451-169]

$114513 \mathrm{E} \quad$ Methods used for testing large-size mirrors surface figure and on and off-axis surfaces optical parameters at the stage of figuring[11451-171]

$114513 F \quad$ The Shack-Hartmann wavefront sensor for the Rubin Observatory [1 1451-172] 
POSTER SESSION: TECHNOLOGIES FOR CRYOGENIC INSTRRUMENTS

$114513 M \quad$ Cryo-vacuum system for low temperature thermal cycling of MCT detectors [11451-208]

$114513 P \quad$ Development of 30mW@4K hybrid J-T cooler for space application [1 1451-211]

$114513 Q \quad$ Vibration reduction for stirling cryocooler system [11451-212]

$114513 R \quad$ Design update of the central wheel mechanism [11451-215]

POSTER SESSION: CORONOGRAPHY AND HIGH CONTRAST IMAGING

11451 3V Development of a space spectropolarimeter for full Stokes parameters retrieval [11451-220]

$114513 X \quad$ Optical sensitivity analyses of various reflective systems: on-axis, common off-axis, and confocal off-axis designs [11451-223]

$114513 Y \quad$ Speckle reduction technique using the self-coherent camera for the common-path visible nulling coronagraph [11451-224]

POST-DEADLINE

1145140 Surface-relief gratings with anti-reflective nanostructures for panchromatic astronomical low/medium/high resolution spectroscopic surveys [11451-270]

$1145141 \quad$ Illuminating the degradation of lithium fluoride mirror coatings in humid environments [1 1451-271]

$1145142 \quad$ PULSAR: development of a mirror tile prototype for future large telescopes robotically assembled in space [1 1451-272]

$1145144 \quad$ Vortex phase masks of topological charge 4 and higher with diamond subwavelength gratings [11451-274]

1145145 Development and implementation of crossed-sine wavefront sensor for simultaneous high spatial resolution imaging [1 1451-275]

$1145147 \quad$ New high-accuracy solar guiding test technology [11451-277]

1145149 Retardation of the oxidation of aluminum thin films in low-oxygen and cryogenic environments [1 1451-279]

$114514 \mathrm{~A}$ Design and analyses on a single panel of thermal enclosure for ELT class of instruments: mechanical structure and electrical interface [11451-280] 
$114514 \mathrm{C} \quad$ Factors, affecting mirror figure stability, and methods used to eliminate them [1 1451-282]

$114514 \mathrm{D}$ The Talbot effect's impact on the high contrast imaging modes of METIS [1 1451-283]

$114514 \mathrm{E} \quad$ An aplanatic meniscus lens for correcting astigmatism in Ritchey-Chrétien telescopes [1 1451-285]

$114514 \mathrm{~F} \quad$ Manufacture of $\mathbf{8 . 4} \mathbf{m}$ segments for the GMT primary mirror [11451-289]

\section{POSTER SESSION: NOVEL DESIGNS AND CONCEPTS}

$114514 G \quad$ ELT-HIRES the High Resolution Spectrograph for the ELT: status of the polarization ray tracing tool for the polarimetric unit [11451-131]

114514 The ASTRA project: a doorway to future astrometry [11451-134]

$114514 \mathrm{~K}$ Towards the attitude determination of nano-satellites with thermal imaging sensors [11451-136]

1145140 Polarization model for the multi-application solar telescope at the Udaipur Solar Observatory [11451-140]

$114514 Q \quad$ Improved AFGSM (Alignment-Free Gapless Segmented Mirror) for astronomical large telescope [11451-143]

$114514 R \quad$ Design of the automated $\mathrm{CO}_{2}$ optics cleaning system for the Thirty Meter Telescope [11451-144]

\section{POSTER SESSION: ACTIVE INSTRUMENTS AND TELESCOPE STRUCTURES}

$114514 \mathrm{~T} \quad$ Automated reflective optical system alignment with focal plane sensing and Kalman filters [1 1451-94]

$114514 \mathrm{U} \quad$ Ultra-sonic super compact rotary stage for arrayed wide-angle camera system: prototype results [1 1 1451-95]

$114514 \mathrm{~V} \quad$ Fast modulation and dithering for the NFIRAOS pyramid wavefront sensor [1 1451-96]

$114514 Z$ Development of a cold chopper for TAO/MIMIZUKU [1 1451-101]

$1145150 \quad$ Warping harness actuator for the Thirty Meter Telescope primary mirror segments [11451-102]

1145152 Development status of the segmented mirror control system in Seimei Telescope [11451-105]

$1145153 \quad$ Selecting optimal glass combinations for atmospheric dispersion correctors [1 1451-106] 
1145157 The HinOTORI Telescope and its remote control system [11451-112]

POSTER SESSION: COATING, FILTERS, AND GRATINGS TECHNOLOGY

$114515 \mathrm{~A}$ Developing the wide-spectral coverage, very high-efficiency grisms for MOIRCS on Subaru Telescope [11451-177]

11451 5B Machining a YJ band grism in ZnSe for the Rapid Infrared Imager Spectrograph (RIMAS): improvements in technique [11451-178]

$1145151 \quad$ Precise blaze angle measurements of lithographically fabricated silicon immersion gratings [11451-185]

$114515 \mathrm{~J}$ In-situ monitoring of Subaru Telescope's optical performance using a portable spectrophotometer [11451-186]

$114515 K \quad$ Dichroic coatings for astronomical instrumentation [11451-189]

$114515 \mathrm{~L} \quad$ Materion precision optics LAO (Large Area Optics) lab [1 1451-190]

$114515 \mathrm{~N}$ Experimental demonstration of a Gabor zone-plate hologram for Space Exoplanet Telescope [1 1451-192]

1145150 Optomechanical design of PAWS, the Potsdam Arrayed Waveguide Spectrograph [11451-193]

$114515 Q \quad$ Spectral envelope control for a flat frequency comb spectrum [11451-196]

$114515 R \quad$ Upgrades to the Magellan Telescopes mirror coating process [11451-197]

$114515 \mathrm{~T}$ Design and fabrication of metamaterial anti-reflection coatings for the Simons Observatory [11451-199]

11451 5V HARMONI - first light spectroscopy for the ELT: broadband reflective coatings [11451-201]

11451 5W HARMONI: Characterising the line-spread-function with a tunable Fabry-Pérot etalon [11451-202]

11451 5X Transmittance measurement of low/high-resistivity of CdZnTe at cryogenic temperature for material selection of the immersion grating of SPICA SMI [1 1451-203]

$114515 Y \quad$ RIMAS: testing, and categorization of grism spectral performance [1 1451-269]

POSTER SESSION: OPTICAL FIBERS AND POSITIONERS

1145164 An integrated field unit with thousands of optical fibers for a solar telescope [11451-231] 
1145166 Multi-core fiber-fed integral field spectrograph (MCIFU) - III: an ultrafast laser inscribed photonic reformatter and mask [1 1451-233]

1145168 Optimization of telescope focal ratios for MLA-fiber coupled integral field units [11451-236]

$114516 \mathrm{~A}$ Application of atmospheric $\mathrm{OH}$ suppression technology to ground-based infrared astronomy [11451-238]

$114516 \mathrm{~B} \quad$ Broadband mid-IR fiber optics for heterodyne spectroscopy in solar system exploration missions [11451-239]

$114516 \mathrm{C}$ Development of the liquid nitrogen cooled hollow core waveguide fiber for the mid-infrared region [11451-240]

$114516 \mathrm{~F} \quad$ Fiber modal noise mitigation by a rotating double scrambler [11451-243]

$114516 G$ Testbed for coupling starlight into fibers and astrophotonic instruments [1 1451-244]

$1145161 \quad$ Assemblies of the microlenses on the front-end fibres of MOONS [11451-247]

$114516 \mathrm{~J} \quad$ Final characteristics and performances of the fibres of MOONS [11451-248]

$114516 \mathrm{~L} \quad$ Development of an integrated near-IR astrophotonic spectrograph [11451-250]

$114516 \mathrm{M}$ Equalization and hole location modeling for large scale non-planar focal plane [11451-251]

$114516 Q \quad$ Fiber assignment for multi-object fiber-fed spectrographs [11451-255]

$114516 R$ Design and study of visual fast detecting instrument for fiber positioners [11451-256]

$114516 \mathrm{~W}$ Development and characterization of a precisely adjustable fiber polishing arm [11451-261]

$114516 Y$ An innovative integral field unit upgrade with 3D-printed micro-lenses for the RHEA at Subaru [11451-263]

POSTER SESSION: SLIT SPECTROSCOPY AND IMAGE SLICERS

$1145171 \quad$ MAVIS IFU with AO for VLT: image slicer concept and design [11451-266] 
Proc. of SPIE Vol. 11451 1145101-12 Downloaded From: https://www.spiedigitallibrary.org/conference-proceedings-of-spie on 26 Apr 2023
Terms of Use: https://www.spiedigitallibrary.org/terms-of-use 